\title{
Medical procedure patents worry trade agreement critics
}

$\mathrm{G}$ roups tracking international negotiations on the TransPacific Partnership Agreement (TPPA) are raising concerns over efforts by the United States to include the patenting of diagnostic, therapeutic and surgical procedures.

There could be substantial costs to health care providers if the 12-nation trade agreement were to include patents on medical procedures, says Peter Maybarduk, director of the Global Access to Medicines Program for Public Citizen, a nonprofit advocacy group for citizen rights based in Washington, DC.

"Physicians or health care providers could be charged additional royalties on top of the one-time cost of a medical device each time they practise a patented method. Essentially, except for when a surgeon uses her bare hands, surgical methods would be patent-eligible in nations that sign an agreement allowing these patents," says Maybarduk. "Physicians and health care providers who infringe medical procedure patents may be liable to pay high damages."

These additional treatment costs, however, are difficult to estimate, says Dr. John Frangioni, a molecular imaging innovator at Harvard Medical School in Boston, Massachusetts, who has worked with industry to develop medical procedures that use proprietary technologies. The cost to health care providers depends on the cost to develop and test a new medical procedure.

If developers of new procedures use proprietary technologies, they must pay a number of fees, notes Frangioni, and every licensing deal is different. Costs could include up-front licensing fees (up to US\$500 000), annual royalties (typically US\$500050000 , depending on market size) and milestone payments for clinical trials (typically US\$100 000-\$250000 per phase).

"Without patent protection, nothing moves forward," says Frangioni, who stresses that the costs of developing

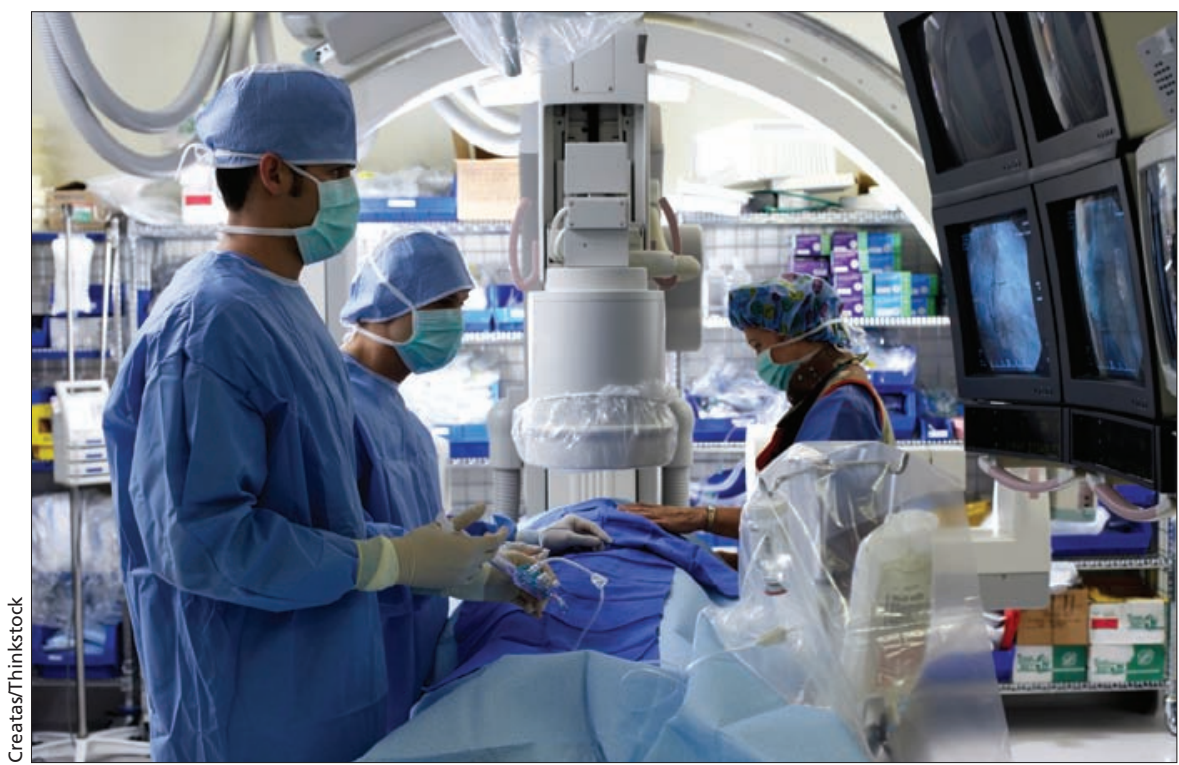

Patenting new diagnostic, surgical and therapeutic procedures will increase medical costs, limit patient options and lead to lawsuits, warn critics of the practice.

devices and drugs force innovators to patent their work.

"The manufacturing and approval processes are hugely expensive" he explains. "You can't do the procedure until you have an FDA/EMA [Food and Drug Administration/European Medicines Agency]-approved device and an FDA/EMA-approved drug, both of which are approved for that particular indication."

The US and Australia are the only countries that allow medical procedure patents, says Public Citizen, while noting that as of 2009, more than 80 countries had banned them. The European Patent Convention states that patents shall not be granted on "methods for treatment of the human or animal body by surgery or therapy and diagnostic methods practised on the human or animal body." Numerous free-trade agreements, including the North American Free Trade Agreement, permit members to exclude medical procedures from patentability.

US patents on surgical, diagnostic and treatment methods stem from a 1952 US Patent Act amendment that added "new and useful processes" to the list of patentable entities. By 1995 , as many as fifteen medical procedures were being patented weekly, Public Citizen noted in a 2013 briefing.

Inclusion of these patents in the TPPA could be especially problematic in lower income nations, warns Judit Rius Sanjuan, US director of the Access Campaign for Médecins Sans Frontières. "These patents could affect the ways medical providers practise by preventing them from using patented methods."

The US push for including medical procedure patents in the TPPA was revealed in a draft of the agreement's intellectual property chapter that was published by Wikileaks last November. According to the document, which includes descriptions of the negotiating positions adopted by each participating nation, the US is the only country that supports inclusion of medical procedure patents in the agreement.

"The US government wouldn't ask for this if it didn't want it," Maybarduk warns. "The US usually asks for everything and typically gets most of what it wants." - Paul Christopher Webster, Toronto, Ont.

CMAJ 2014. DOI:10.1503/cmaj.109-4764 